\title{
SISTEM INFORMASI GEOGRAFIS PETUNJUK ARAH LOKASI PONDOK PESANTREN DARUD DA'WAH WAL-IRSYAD (DDI) BERBASIS WEB
}

\author{
Soeparto Haseng \\ Manajemen Informatika, Politeknik Informatika Nasional Makassar \\ Email: idsoeparto@gmail.com
}

\begin{abstract}
ABSTRAK
Eksistensi pesantren sebagai lembaga tertua pendidikan islam di nusantara diakui telah memiliki andil dan peran yang besar dalam sejarah perjuangkan bangsa Indonesia. Di samping itu, pesantren juga mempunyai peranan penting dalam sistem pendidikan nasional. Darud Dakwah Wal Irsyad (DDI) adalah salah satu organisasi islam yang berbasis Pendidikan pesantren. Sejak peralihan Madrasah Arabiyah Islamiyah (MAI) pada tahun 1947 hingga sekarang ini Darud Dakwah Wal Irsyad (DDI) telah membina pesantren dan madrasah yang telah tersebar keseluruh pelosok tanah air. Penelitian ini bertujuan untuk merancang dan membuat sistem informasi geografis petunjuk arah lokasi Pondok Pesantren Darud Da'wah Wal Irsyad (DDI) berbasis web. Sistem ini diharapkan dapat membantu memudahkan masyarakat untuk melakukan pencarian lokasi pesantren dan Bagi Pondok Pesantren Darud Da'wah Wal Irsyad untuk meningkatkan informasi pendukung terkait tentang lokasi cabang Pondok Pesantren Darud Da'wah Wal Irsyad (DDI) yang tersebar di seluruh Indonesia. Metode pengumpulan data penelitian ini yaitu dengan studi literatur. Adapun desain model sistem pada penelitian ini dengan menggunakan UML (Unified Modelling Languange) mencakup use case diagram, class diagram, sequence diagram dan activity diagram. Sistem ini berhasil dirancang dengan baik dan dapat memudahkan para pengguna untuk mencari informasi mengenai lokasi Pondok Pesantren Darud Da'wah Wal Irsyad (DDI) yang tersebar di Indonesia dengan adanya sistem ini, pengguna dapat lebih mudah mendapatkan informasi dari beberapa Pondok Pesantren Darud Da'wah Wal Irsyad (DDI) dengan waktu pencarian yang terbilang singkat dan dari sumber yang terpercaya.
\end{abstract}

Kata Kunci: Geografis, Informasi, Lokasi, Pesantren, Website

\section{ABSTRACT}

The existence of Islamic boarding schools as the oldest institution of Islamic education in the archipelago is acknowledged to have had a big role and role in the history of fighting for the Indonesian people. Also, Islamic boarding schools also have an important role in the national education system. Darud Dakwah Wal Irsyad (DDI) is one of the Islamic organizations based on Islamic boarding schools. Since the transition of the Arabiyah Islamiyah Madrasah (MAI) in 1947 to the present Darud Dakwah Wal Irsyad (DDI) has built Islamic boarding schools and madrassas that have spread throughout the country. This study aims to design and create a geographic information system to guide the location of the web-based Darud Da'wah Wal Irsyad Islamic Boarding School (DDI). This system is expected to help make it easier for the community to search the location of Islamic boarding schools and For Islamic Boarding School Darud Da'wah Wal Irsyad to improve related information about the location of the branch of Darud Da'wah Wal Irsyad Islamic Boarding School (DDI) spread throughout Indonesia. The 
method of data collection in this study is the literature study. The design of the system model in this study using UML (Unified Modeling Language) includes use case diagrams, class diagrams, sequence diagrams, and activity diagrams. This system has been well designed and can make it easier for users to find information about the location of the Darud Da'wah Wal Irsyad Islamic Boarding School (DDI) spread throughout Indonesia with the existence of this system, users can more easily obtain information from several Darud Da'wah Islamic Boarding Schools Wal Irshad (DDI) with relatively short search times and from trusted sources.

\section{Keywords: Geographic, Information, Location, Boarding School, Website}

\section{Pendahuluan}

Eksistensi pesantren sebagai lembaga tertua pendidikan islam di nusantara diakui telah memiliki andil dan peran yang besar dalam sejarah perjuangkan bangsa Indonesia. Di samping itu, pesantren juga mempunyai peranan penting dalam sistem pendidikan nasional. Sudah tidak diragukan lagi bahwa pesantren memiliki kontribusi yang nyata dalam pembangunan pendidikan nasional. Apalagi dilihat secara historis, pondok pesantren memiliki pengalaman yang sangat luar biasa dalam membina dan mengembangkan masyarakat. Bahkan pondok pesantren mampu meningkatkan peranannya secara mandiri dengan menggali potensi yang dimiliki masyarakat di sekelilingnya.

Meningkatkan dan mengembangkan peran serta pesantren dalam proses pembangunan merupakan langkah strategis dalam membangun masyarakat, daerah, bangsa, dan negara. Terlebih dalam kondisi yang telah mengalami krisis moral seperti sekarang ini. Pesantren sebagai lembaga pendidikan yang membentuk dan mengembangkan nilai-nilai moral, harus menjadi pelopor sekaligus inspirator pembangkit moral bangsa. Sehingga pembangunan, khususnya di bidang pendidikan tidak menjadi hampa melainkan lebih bernilai dan bermakna.
Darud Dakwah Wal Irsyad (DDI) adalah salah satu organisasi islam yang berbasis Pendidikan Pesantren. Sejak peralihan Madrasah Arabiyah Islamiyah (MAI) pada tahun 1947 hingga sekarang ini Darud Dakwah Wal Irsyad (DDI) telah membina pesantren dan madrasah yang telah tersebar keseluruh pelosok tanah air yang kini meliputi 14 Provinsi yaitu Sulawesi Selatan, Sulawesi Tengah, Sulawesi Tenggara, Kalimantan Timur, Kalimantan Barat, Kalimantan Selatan, Provinsi Jambi, Riau, Jawa Timur, Jawa Barat, Jawa Tengah, Nusa tenggara, Jakarta, Bali, dan Irian. Masyarkat masih banyak yang belum tahu lokasi - lokasi Darud Dakwah Wal Irsyad (DDI) yang tersebar dipelosok tanah air tersebut.

Saat ini perkembangan teknologi sudah semakin pesat yang diiringi pula dengan kemajuan dalam pembuatan sistem informasi. Penggunaan teknologi informasi bertujuan untuk mencapai efisiensi dalam berbagai aspek pengelolaan informasi, dalam lingkungan lembaga pendidikan, sistem informasi merupakan alat bantu yang sangat diperlukan. Sistem informasi geografi dapat menghubungkan data spasial seperti letak geografis atau letak astronomis menggunakan data non spasial. Dengan begitu, pengguna SIG dapat membuat peta serta menganalisa informasi menggunakan berbagai cara serta metode. 


\section{Landasan Teori}

\subsection{Sistem Informasi Geografis (SIG)}

Menurut Masykur (2014 : 181) Sistem Informasi Geografis (SIG) / Geographic Information System (GIS) adalah suatu sistem informasi berbasis komputer, yang digunakan untuk memproses data spasial yang ber-georeferensi (berupa detail, fakta, kondisi, dsb) yang disimpan dalam suatu basis data dan berhubungan dengan persoalan serta keadaan dunia nyata (real world).

\subsection{Pondok Pesantren}

Menurut asal katanya pesantren berasal dari kata "santri" yang mendapat imbuhan awalan "pe" dan akhiran "an" yang menunjukkan tempat, maka artinya adalah tempat para santri. Terkadang pula pesantren dianggap sebagai gabungan dari kata "santri" (manusia baik) dengan suku kata "tra" (suka menolong) sehingga kata pesantren dapat diartikan tempat pendidikan manusia baik-baik (Zarkasy, 1998: 106).

\subsection{Darud Da'wah Wal Irsyad (DDI)}

Darud Da'wah Wal Irsyad (DDI) adalah salah satu organisasi islam yang berbasis Pendidikan pesantren. Sejak peralihan Madrasah Arabiyah Islamiyah (MAI) pada tahun 1947 hingga sekarang ini Darud Dakwah Wal Irsyad (DDI) telah membina pesantren dan madrasah yang telah tersebar keseluruh pelosok tanah air yang kini meliputi 14 Provinsi yaitu Sulawesi Selatan, Sulawesi Tengah, Sulawesi Tenggara, Kalimantan Timur, Kalimantan Barat, Kalimantan Selatan, Provinsi Jambi, Riau, Jawa Timur, Jawa Barat, Jawa Tengah, Nusa tenggara, Jakarta, Bali, dan Irian Jaya.

\subsection{PHP}

PHP merupakan singkatan dari "PHP: Hypertext Preprocessor", adalah sebuah bahasa scripting yang terpasang pada HTML. Sebagian besar sintaks mirip dengan bahasa C, Java, asp dan Perl, ditambah beberapa fungsi PHP yang spesifik. (Nore, 2013 : 5) Tujuan utama bahasa ini adalah untuk memungkinkan perancang web untuk menulis halaman web dinamik dengan cepat.

\subsection{MySQL}

MySQL adalah sebuah perangkat lunak sistem manajemen basis data SQL (Database Management System) atau DBMS yang multithread, multi-user. MySQL adalah Relational Database Management System (RDBMS) yang didistribusikan secara gratis dibawah lisensi GPL (General Public License). MySQL sebenarnya merupakan turunan salah satu konsep utama dalam database sejak lama, yaitu SQL (Structured Query Language). SQL adalah sebuah konsep pengoperasian database, terutama untuk pemilihan atau seleksi dan pemasukan data, yang memungkinkan pengoperasian data dikerjakan dengan mudah secara otomatis.

\subsection{WEB.}

Website atau situs dapat diartikan sebagai kumpulan halaman halaman yang digunakan untuk menampilkan informasi, teks, gambar diam atau bergerak, animasi, suara, dan atau gabungan dari semuanya itu, baik yang bersifat statis maupun dinamis yang membentuk satu rangkaian bangunan yang saling berkait dimana masing masing dihubungkan dengan jaringan jaringan halaman. (Utama, 2011 : 360) 


\subsection{HTML}

HTML (Hyper Text Markup Language) merupakan salah satu format yang digunakan dalam pembuatan dokumen dan aplikasi yang berjalan di halaman web. Oleh karena itu agar dapat membuat program aplikasi di atas halaman web, terlebih dahulu harus mengenal dan menguasai HTML. Walaupun sekarang telah banyak paket aplikasi yang dapat digunakan untuk membuat

Halaman web secara WYSIWWIG (what you see is what you get) seperti frontpage, DreamWaver, Netscape Composer dan masih banyak lagi. (Marlena \& Sasongko, $2010: 8$ )

HTML (Hyper Text Markup Language) merupakan salah satu format yang digunakan dalam pembuatan dokumen dan aplikasi yang berjalan di halaman web. Oleh karena itu agar dapat membuat program aplikasi di atas halaman web, terlebih dahulu harus mengenal dan menguasai HTML. Walaupun sekarang telah banyak paket aplikasi yang dapat digunakan untuk membuat

halaman web secara WYSIWWIG (what you see is what you get) seperti frontpage, DreamWaver, Netscape Composer dan masih banyak lagi. (Marlena \& Sasongko, 2010 : 8)

\subsection{XAMPP}

Xampp adalah satu paket komplit web server yang mudah dipasang di berbagai system operasi. Dalam paketnya sudah terkandung Apache (web server), MySql (database), PHP (server side scripting), dan berbagai pustaka bantu lainnya. Xampp tersedia untuk linux, windows, Macos maupun solaris sehingga sangat memudahkan membuat web server multiplatform. (Nore, $2013: 17$ )

\subsection{CSS}

Cascading Style Sheet (CSS) adalah salah satu bahasa untuk mengatur tampilan dalam web yang berfungsi memisahkan antara desain dengan content. CSS dapat ditulis untuk mendefinisikan ulang tag-tag HTML ataupun dengan menambah atribut id dan class pada tag HTML. (Nugroho Cahyo \& Purnama Eka, 2012 : 48)

\subsection{Apache}

Apache adalah sebuah nama web server yang bertanggung jawab pada request-response HTTP dan logging informasi secara detail (kegunaan basicnya). Apache juga diartikan sebagai suatu web server yang kompak, modular, mengikuti standar protokol HTTP, dan tentu saja sangat digemari. Apache memiliki fitur-fitur canggih seperti pesan kesalahan yang dapat dikonfigurasi, autentikasi berbasis basis data dan lain-lain. Apache juga didukung oleh sejumlah antarmuka pengguna berbasis berbasis grafik (GUI) yang memungkinkan penanganan server menjadi mudah. (Zakiah \& Supriatna, $2015: 25$ )

\section{Metodologi Penelitian}

\subsection{Metode Pengumpulan Data}

Metode pengumpulan data yang digunakan dalam mengumpulkan informasi kebutuhan penelitian ini adalah melalui observasi, wawancara dan studi literatur.

\subsection{Desain Model Sistem}

Adapun desain model sistem pada penelitian ini dengan menggunakan UML (Unified Modelling Languange) mencakup 
use case diagram, class diagram, sequence diagram dan activity diagram.

A. Use Case Diagram

Rancangan use case diagram ditunjukkan pada gambar 1 berikut :

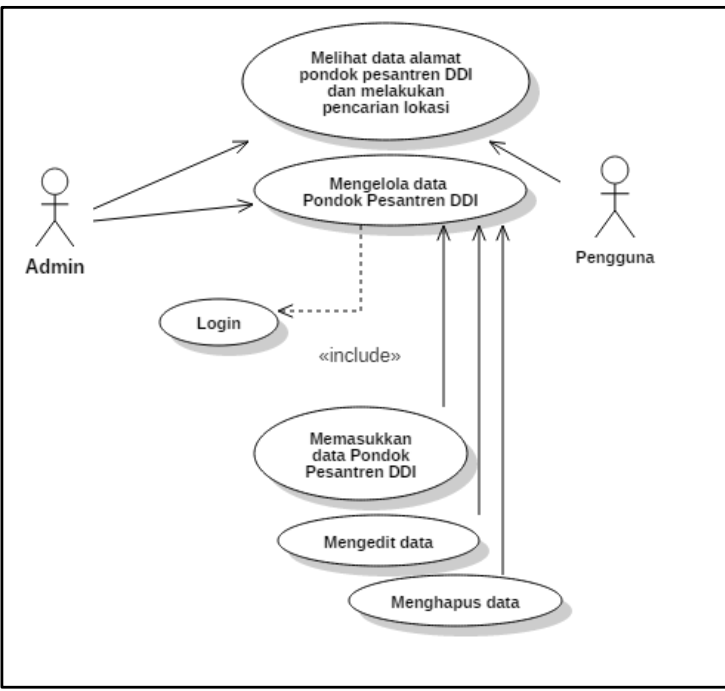

Gambar 1: Use Case Diagram

\section{B. Class Diagram}

Rancangan Class diagram ditunjukkan pada gambar 2 berikut :

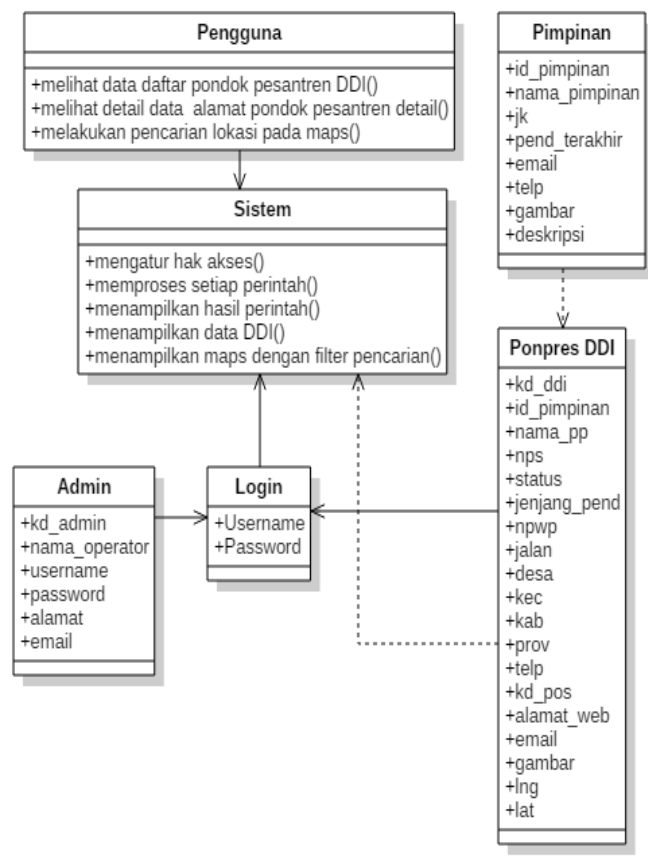

Gambar 2 : Class Diagram

\section{Sequence Diagram}

Rancangan Sequence diagram pada ditunjukkan pada Gambar 3 berikut.

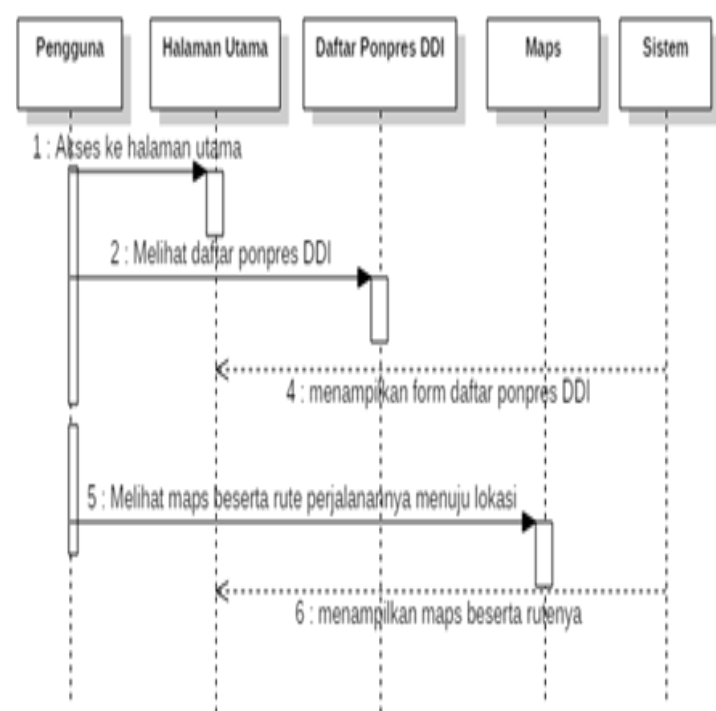

Gambar 3: Sequence Diagram

D. Activity Diagram

Rancangan activity diagram ditunjukkan pada gambar 4 berikut.

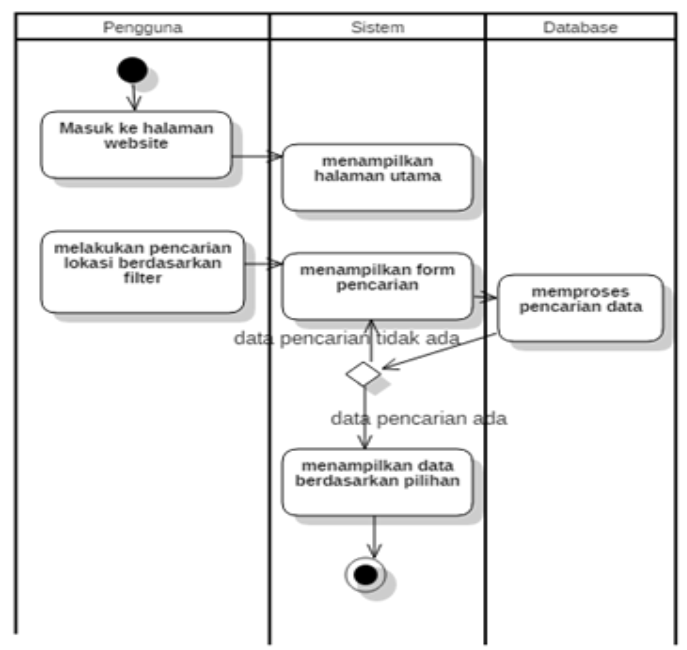

Gambar 4: Activity Diagram

\section{Hasil dan Pengujian Sistem}

\subsection{Hasil}

A. Tampilan login

Tampilan ini merupakan output dari menu login yang digunakan oleh admin maupun operator untuk mendapat akses 
atas data Pondok pesantren DDI bersangkutan. Halaman Login terlihat pada gambar 5 berikut :

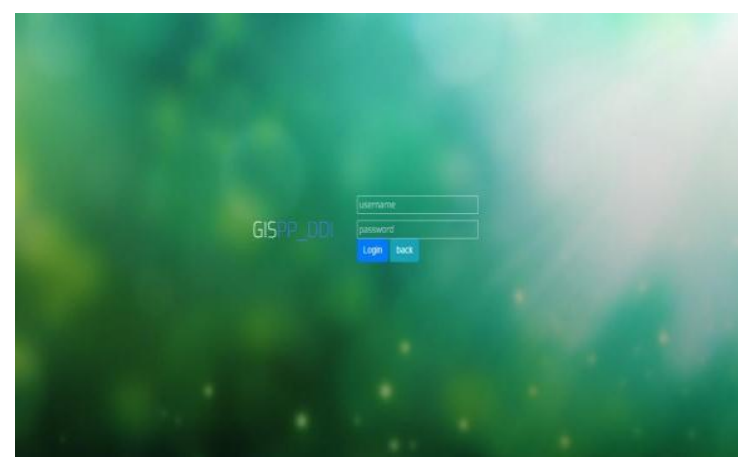

Gambar 5: Tampilan Login Admin

B. Halaman Utama Admin

Tampilan utama admin merupakan tampilan halaman setelah berhasil login. Pada halaman ini terdapat dua menu yaitu pimpinan dan tabel DDI, di mana admin dapat mengelolah semua data. Ditunjukkan pada gambar 6 berikut :

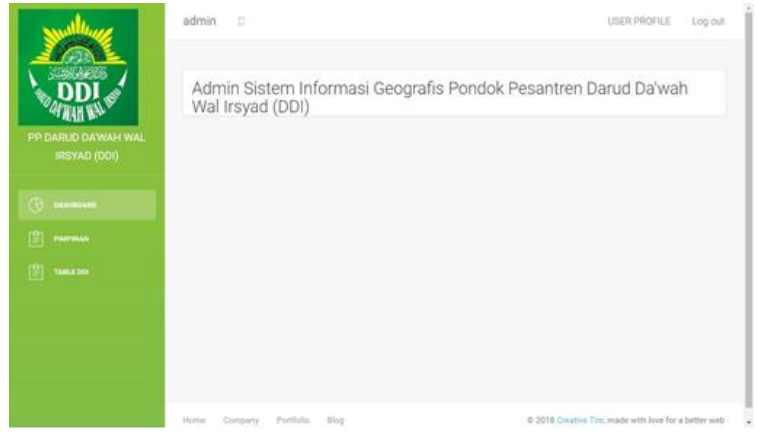

Gambar 6: Tampilan Halaman Utama Admin

C. Tampilan Maps Pondok Pesantren DDI Tampilan ini merupakan tampilan yang muncul apabila menu maps diklik, di mana pada halaman ini kita dapat mencari lokasi pondok pesantren berdasarkan nama pondok pesantren yang kita pilih. Begitu juga dengan tombol rute di bagian bawah yang berfungsi untuk menampilkan rute perjalanan menuju ke arah lokasi pondok pesantren yang akan dituju. Tampilan tersebut ditunjukan pada Gambar 7 dan Gambar 8 berikut ;

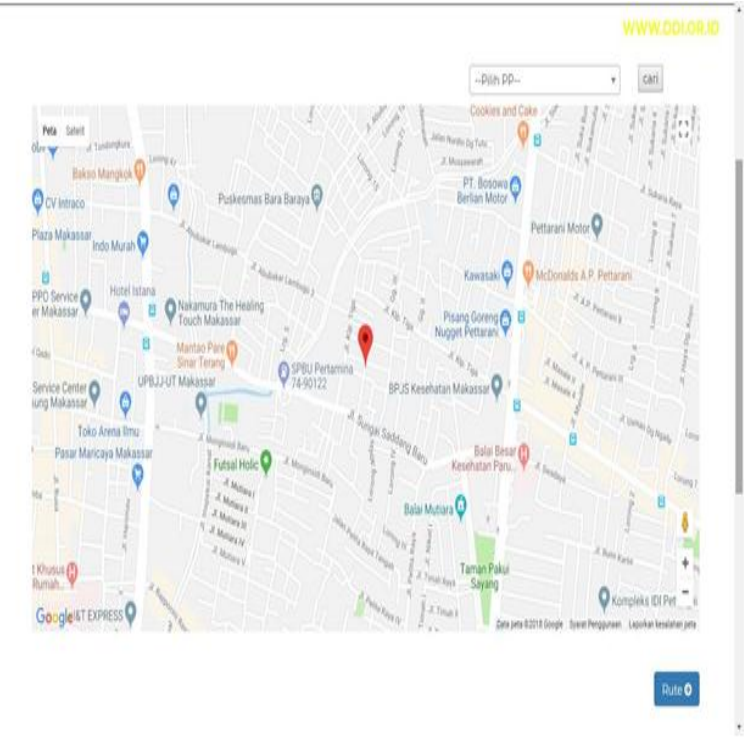

Gambar 7: Tampilan menu maps

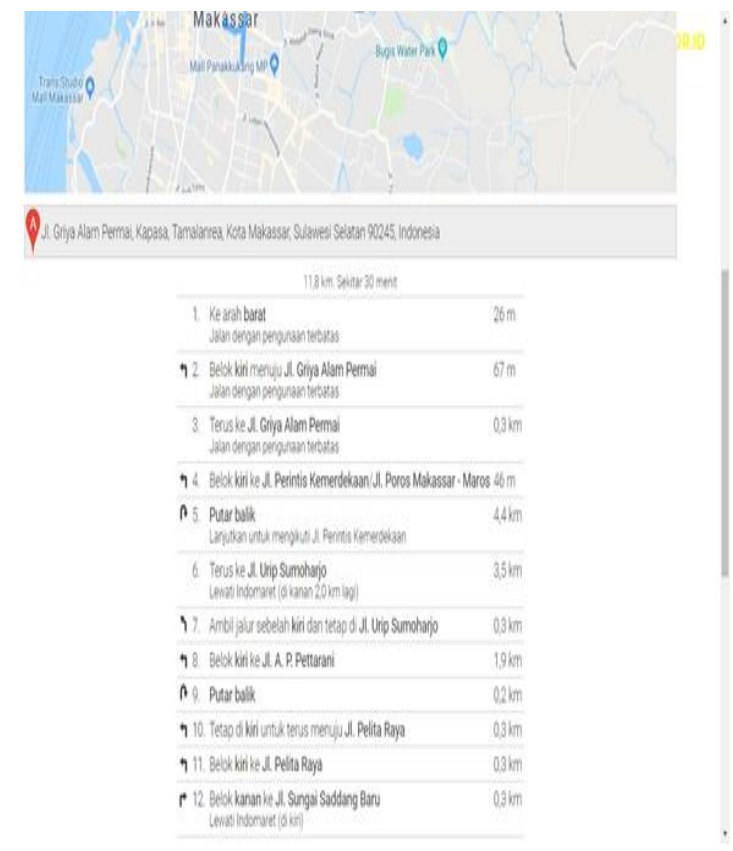

Gambar 8: Tampilan rute ke arah tujuan

\subsection{Pengujian Sistem}

Dari hasil pengujian sistem didapatkan bahwa semua form berjalan sesuai dengan yang diharapkan. Seperti pada tabel 1 berikut ini : 
Tabel 1. Hasil pengujian sistem

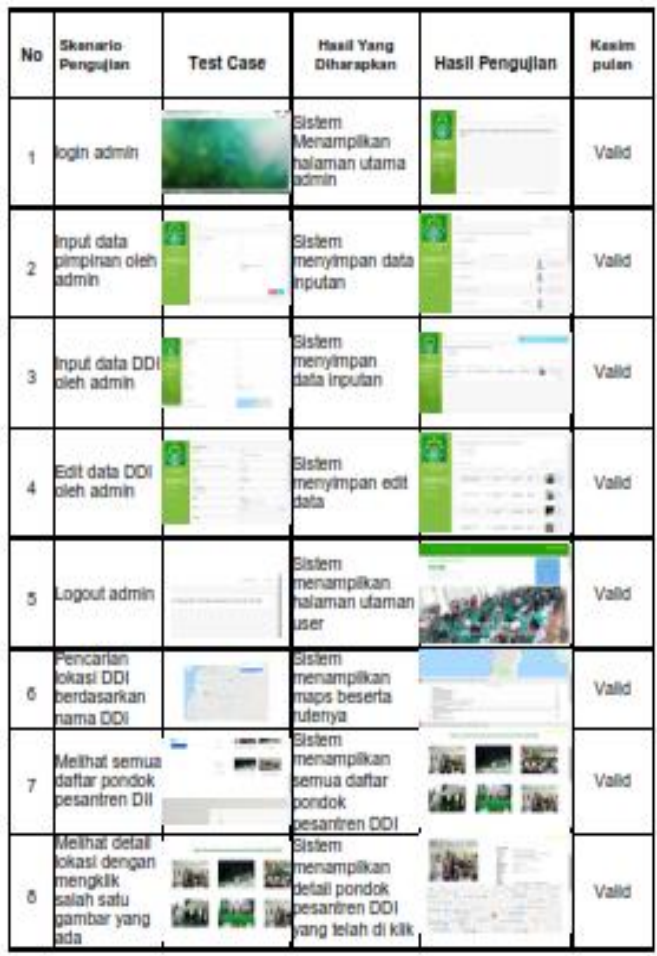

\section{Kesimpulan dan Saran}

\subsection{Kesimpulan}

Sistem Informasi Geografis Pondok Pesantren Darud Da'wah Wal Irsyad (DDI) Berbasis Website ini berhasil dirancang dengan baik dan dapat memudahkan para pengguna untuk mencari informasi mengenai lokasi Pondok Pesantren Darud Da'wah Wal Irsyad (DDI) yang tersebar di Indonesia dengan adanya sistem ini, pengguna dapat lebih mudah mendapatkan informasi dari beberapa Pondok Pesantren Darud Da'wah Wal Irsyad (DDI) dengan waktu pencarian yang singkat dan dari sumber yang terpercaya. Sistem ini mudah diakses oleh siapa saja.

\subsection{Saran}

Saran yang diharapkan yaitu perlu adanya pengembangan sistem dengan melihat perkembangan zaman untuk menyesuaikan dengan teknologi yang akan terus berkembang di waktu mendatang. Dalam hal ini perlu adanya pengembangan sistem dari berbasis website menjadi berbasis mobile.

\section{DAFTAR PUSTAKA}

Marlena, N., \& Sasongko, D. (2010). Pembuatan Website Profil Pada Sekolah Menengah Pertama (SMP) Negeri 2 Kartasura. Jurnal Speed, 2(3), 7-12

Masykur, F. (2014). Implementasi Sistem Informasi Geografis Menggunakan Google Maps Api Dalam Pemetaan Asal Mahasiswa. Jurnal SIMETRIS, 5(2), 181-186.

Nore, V. N. (2013). Perancangan Sistem Informasi Penjualan dan Pemesanan Produk Berbasis Web. Universitas Widyatama Bandung.

Nugroho Cahyo, N., \& Purnama Eka, B. (2012). Perancangan Inovasi Konten Web Radio Streaming Dan Podcasting Pada Radio Puspa Fm Pacitan, 4(4), 47-55.

Utama, Y. (2011). Sistem Informasi Berbasis Web Jurusan Sistem Informasi Fakultas Ilmu Komputer Universitas Sriwijaya. Jurnal Sistem Informasi (JSI), 3(2), 359370.

Zarkasyi, Amal Fathullah.(1998). Pondok Pesantren Sebagai Lembaga dan Dakwah. Jakarta: Gema Insani Press.

Zakiah, A., \& Supriatna, A. (2015). Aplikasi Pengelolaan Arsip Surat Berdasarkan Peraturan Bersama Kepala Anri Nomor 18 th.2009. Prosiding Sentia 2015, 7, 24-29. 